\title{
Sob o signo de Napoleão. A Súplica constitucional de 1808
}

Under Napoleon's Sign. The 1808's

Constitutional Pledge

\section{António Manuel Hespanha}

Professor na Faculdade de Direito da Universidade Nova de Lisboa

\section{Resumo}

A partida do rei e da corte para o Brasil não congelou os assuntos políticos em Portugal. Pelo contrário, a ausência do rei, a entrega do governo a uma Junta menos legitimada, as invasões francesas e a influência das idéias liberais vindas da Europa, veiculadas, nomeadamente pelas lojas maçônicas, provocaram uma efervescência política de que Junot se deu conta e que tentou explorar a favor dos interesses da França, apesar de tudo portadora do facho da Revolução. É neste ambiente que se insere o pedido a Napoleão de uma constituição para Portugal, bem como as movimentações, autônomas ou promovidas pelos ocupantes, de elites políticas como a do envio de uma embaixada "representativa" ao Imperador, que aqui se descreve. Traz em anexo dois documentos originais: a "Súplica dirigida a Napoleão, em 24.05.1807, pela Junta dos Três Estados" e o "Estatuto Constitucional do Ducado de Varsóvia".

\section{Abstract}

In Portugal, political affairs didn't cease to exist once the Royal Family and courtesans fled to Brazil. Quite the opposite, a complex situation that involved the King's absence, a government held by a Committee not entirely legitimate, the French invasions and the influence of liberal ideas (being spread throughout Europe by Masonic Lodges) generated political turmoil, making it interesting for Junot to profit in the name of French interests (despite all, the bearers of a revolutionary spirit). Napoleon's request of a Constitution for Portugal took place exactly in this context, along with political activities such as the envoy of a "representative" Embassy to the Emperor. Attached to the article two original documents: the "Pledge to Napoleon, May 24th 1807, by the Three States Committee" and the "Constitutional Statute of the Warsaw Duchy".

\section{Palavras-chave}

França, Império português, constituição, revolução, história política

\section{Keywords}

France, Portuguese Empire, constitution, revolution, political history 
V., por último HESPANHA, António. M. Guiando a mão invisivel. Direitos, Estado e lei no Constitucionalismo Monárquico português. Coimbra: Almedina, 2004. p.34-45; MESQUITA, António Pedro. 0 pensamento político português no século XIX. Lisboa: Imprensa Nacional, 2006. p. 26-38.

Transcrito numa "Resposta que, vindo da França, fez o Bispo de Coimbra D. Francisco de Lemos a S. Alteza Real, o Principe Regente, Nosso Senhor", num caderno manuscrito, da época, e com aspecto de ser a versão original e autógrafa, que em tempos adquiri num alfarrabista (Livraria histórica Ultramarina, em Lisboa).

3

Os membros da Deputação - com excepção de D. Francisco de Melo, pelas razões que se referirão - ficaram retidos em Bordéus e, depois, em Paris, até 1814 , no fim da guerra.

Em 1810, depois da derrota do exército francês no Buçaco e nas Linhas de Torres e da conseqüente libertação do reino, o bispo regressa a Portugal. Em termos ambíguos, porém: na sequência de um pedido que faz para ir a banhos numa praia bordalesa, pedido que o Imperador converte numa ordem para voltar a Portugal por considerar necessária a sua presença neste reino para tratar de negócios de interesse do Império. 0 bispo procura a protecção de tropas francesas na perigosa travessia de Espanha, entra em Portugal (a 9 de Novembro de 1810, por Nave de Aver, perto de Almeida); impedido pelas autoridades militares portuguesas de seguir para o seu bispado de Coimbra, dirigese para o Porto, onde chega a 11 de Dezembro. Ai, por ordem da Junta de Governo, é posto a perguntas do Chanceler da Relação, Manuel António da Fonseca e Gouvêa, em auto assinado em 2 de Abril de 1811, sendo também detalhadamente interrogado acerca dos trajectos de ida e de volta a Bordéus. Tudo isto consta da referida "Resposta que, vindo da França..."; Op.Cit.

5

A Gazeta de Lisboa, de 13.05.1808, dá a notícia da partida de Deputação.

6

"Resposta que, vindo da França...", Op.Cit., fl.161, $n^{\circ} 2$.
As invasões francesas marcam o segundo momento em que, em Portugal, a idéia de uma reforma constitucional andou no ar. Sendo o primeiro, o do chamado Projecto do Novo Código (1786) e da discussão suscitada em torno do seu Livro de Direito Público?.

Em 23 de Fevereiro de 1808, o Marechal Junot, comandante das forças

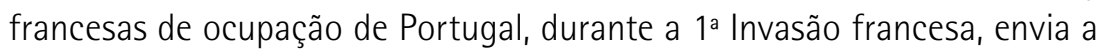
D. Francisco de Melo, bispo de Coimbra e Reitor da Universidade, uma carta em que Ihe transmite que "La Régence, Monsieur, m'avait montré le désir d'envoyer une Députation à sa Majesté, l'Empereur et Roi mon Maître, et ce vœu m'a été exprimé depuis par toutes les classes du Royaume. Sur la compte, que j'ai rendu à Sa Majesté, elle y a consenti, et approuvé la liste, que je lui ai adressée, et dont faites partie. En conséquence vous voudrez bien, Monsieur, prendre vos mesures de manière à être rendu à Bayonne du premier au dix Avril prochain et dans cette ville vous recevrez du Ministre des Relations Extérieures des instructions, qui régleront votre marche ultérieure. Recevez, Monsieur, l'assurance de ma parfaite considération. Junot. Monsieur l'Evêque de Coimbra» 2 .

Esta carta integrava-se num plano de Junot de enviar uma deputação ao imperador, que deveria estar em Baiona nas datas referidas na carta a Francisco de Melo, para o cumprimentar e pedir ainda que reduzisse a contribuição de guerra lançada sobre o país. 0 Senado da Câmara de Lisboa escolheu os nomes dos Deputados: como representante do povo de Lisboa, os desembargadores Joaquim Alberto Jorge e António Tomás da Silva Leitão; por parte do clero, o bispo de Coimbra, D. Francisco de Lemos, o bispo do Algarve e inquisidor geral, D. José Maria de Melo, e o priormor da Ordem de Avis; e por parte da nobreza, os marqueses de Marialva, Penalva e Valença, assim como os dois marqueses de Abrantes, D. Nuno Álvares Pereira de Melo, irmão do duque de Cadaval, o conde de Sabugal, o visconde de Barbacena e D. Lourenço de Lima, futuro Conde de Mafra, que fora o último embaixador em Paris ${ }^{3}$. Considerando que podia prestar algum serviço ao Rei - reflete o bispo numa memória de defesa contra uma sindicância que the foi movida depois do seu regresso ao reino, em $1811^{4}$ - partiu de Lisboa, a 17 de Março de 1808, sem ter recebido quaisquer instruções sobre os assuntos que a Junta iria tratar, nem vindas de Junot, nem de qualquer outro ministro francês 5 . Só em Baiona encontra o resto da delegação, formando então um parecer sobre a matéria a tratar com o Imperador, em carta que dirigiu a D. Lourenço de Lima, que, ainda em Lisboa, fora nomeado presidente da deputação ${ }^{6}$.

Os artigos desta nota eram, segundo ele, os seguintes: $1^{\circ}$. Manter-se a inteireza do reino e restaurar-se a amizade entre o Imperador e o Rei, com o regresso deste ao Reino, a convite do Imperador, por carta autografa que poderia ser levada ao Brasil pela Deputação ; $2^{\circ}$. Subscrição de um tratado que "fixasse as concessões da França a Portugal para o futuro" ; $3^{\circ}$. Caso o Rei não pudesse voltar, envio do Príncipe da Beira como sucessor do Reino ; 4․ Aclamação do Príncipe da Beira como rei, assumindo a regência, até este perfazer 14 anos, um Conselho de Regência, sob a protecção do Imperador. $5^{\circ}-6^{\circ}$. Caso o rei e o príncipe não pudessem ou quisessem voltar ao Reino - o que o bispo não desejava -, o Imperador assumiria a coroa, como assumira a de Itália, com as mesmas condições aceites e juradas por Filipe II de Castela. De Constituição não fala o bispo, que considera estes artigos realistas, prudentes, realizáveis e favoráveis à causa portuguesa, como tal 
"Resposta que, vindo da França, fez o Bispo de Coimbra D. Francisco de Lemos a S. Alteza Real, o Príncipe Regente, Nosso Senhor", fl.161, no 4.

8

"Resposta que, vindo da França...", Op.Cit., fl. $162, n^{\circ} 5$.

9

"Resposta que, vindo da França...", Op.Cit., fl. $162, n^{\circ} 6$.

\section{0}

"Resposta que, vindo da França...", Op.Cit., fl.162, no 11.

11

"'Resposta que, vindo da França...", Op.Cit., fl.163, no 12. A carta é enviada em 27.04 (cf. SERRÃO, Joaquim Verissimo. História de Portugal. Vol. 7, Lisboa: Verbo, 1984, p.37, n.71, cita uma cópia existente na Biblioteca da Academia das Ciências).

\section{2}

"Resposta que, vindo da França...", Op.Cit., fl.163, no 13

13

José Acúrsio das Neves (1766 -1834) foi uma importante figura do pensamento conservador português nas primeiras décadas do séc. XIX. Formado em Leis por Coimbra (1782), tornou-se juiz de fora e corregedor nos Açores, onde exerceu cargos de governo da capitania de Angra. Durante as invasões francesas, reagiu fortemente com a Junta de Regência e contra os afrancesados; neste espirito, escreve, entre 1810-1811, a sua História Geral da Invasão dos Franceses em Portugal, e da Restauração deste Reino, em 5 volumes. Depois da Revolução de 1820, prossegue como partidário do absolutismo, apesar de ter sido eleito deputado para as Cortes Constituintes, cuja obra, porém, rejeita, tomando o partido dos absolutistas, durante 0 domínio dos quais se mantém muito activo e influente. Foi morto, na sua terra, no termo da guerra civil. Edição recente de alguns dos seus escritos. Mais tarde Obras completas de José Acúrsio das Neves. Porto: Afrontamento, 1989. tendo sido aprovados por todos os membros da Deputação e feitos chegar ao Imperador 7.

Chegado o Imperador, recebeu a Deputação. Depois dito palavras de circunstância, de agrado pelo rei e pela família real, veio ao ponto central: Que estava ocupado em unir este reino às outras partes da Europa num sistema continental, defendendo-o das influências estrangeiras que 0 tinham dominado, com o que se referia, naturalmente, aos ingleses; que não tinha animosidade alguma em relação ao rei e sua família, porém que não o podia deixar voltar ao reino, pois ele o abandonara e se colocara sob a protecção inglesa; que, não sendo conveniente que governasse de tão longe um reino, deixava a sorte de Portugal nas mãos da sua nação e do espirito público que mostrasse quanto à sua disposição para se unir ao sistema continental - pela posição de colaboração ou animosidade que tomasse decidiria se essa nação era digna de subsistir e sustentar um principe ou se devia ser absorvida por aquela que, por suposição, mais se aproximasse. Esta última "suposição" referia-se, naturalmente, a Espanha, revelando que continuava viva na mente de Napoleão a sua pristina ideia de dividir Portugal entre um micro-reino satélite da França e a Espanha. Dito isto, despediu a deputação, marcando-Ihe uma nova recepção para Bordéus 8.

Este discurso desanimou muito a deputação ${ }^{9}$, que ficou sensatamente convencida de que o Imperador continuava a seguir o plano secreto, elaborado ainda antes da invasão, de divisão de Portugal entre a França e a Espanha, o qual se tinha manifestado, não apenas nas invasões francesas, como em manobras militares espanholas, de provocação e invasão, na fronteira do território que the haveria de caber na partilha. Para além disso, exigia-se que Portugal renegasse o seu rei, abandonasse "a sua Constituição, suas Leis, seus costumes, e suas relações políticas com as Nações suas amigas e aliadas: todos estes vínculos sociais deviam ser prontos, tudo devia acabar, e não eram, dizia-se, Instituições liberais»" ${ }^{10}$. Esta é a magra referência que D. Francisco de Melo faz a temas constitucionais, indiciando que, ou na charla do Imperador, ou na sua interpretação pelos deputados, tinha havido uma qualquer referência ao carácter não liberal das instituições portuguesas. Quanto à hostilidade de Napoleão para com os Braganças, ela justifica-se bem; não tanto por eles se terem posto sob a proteção dos ingleses, mas porque a sua fixação no Brasil - e a secessão brasileira que isso promovia - tornava mais do que problemática a união das Américas lusa e espanhola sob a égide indirecta da França, quaisquer que fossem os êxitos na Europa e na destruição do domínio inglês no Atlântico e fosse qual fosse a sorte das outras revoltas independentistas na América espanhola.

A deputação, crendo - segundo o bispo - que este discurso seria contraproducente, mandou-o logo para Portugal, para ser publicado 11; ao mesmo tempo, escreve ao Imperador, tentando rebater os seus pontos de vista. 0 encontro com Napoleão frustra-se; o Imperador vem a Bordéus, mas não recebe a Deputação portuguesa, o que esta tem como mais um mau sinal ${ }^{12}$.

A versão que Francisco de Melo dá do teor dos pedidos feitos a Napoleão não confere exactamente com a versão de José Acúrsio das Neves ${ }^{13}$. Segundo este, na alocução da Deputação alude-se ao pedido de um rei e de uma constituição para o reino, garantindo a sua independência em relação 
NEVES, José Acúrsio das. História Geral da Invasão dos Franceses em Portugal, e da Restauração deste Reino. Obras completas de José Acúrsio das Neves. Porto: Afrontamento, 1989, Vol. Il. p.15 ss.

\section{5}

Sobre ele, v., agora, FREITAS, Pedro Miguel Martins Gonçalves Caridade. Um testemunho na transição para o século XIX: Ricardo Raimundo Nogueira. Coimbra: Almedina, 2005. Antes, MACEDO, José Agostinho de. Elogio histórico do ilustrissimo e excelentissimo Ricardo Raimundo Nogueira, conselheiro de Estado. Lisboa: Imp. Regia, 1827. A sua participação nesta iniciativa é incerta: cf. HOMEM, António Pedro Barbas. Algumas notas sobre a introdução do Código Civil de Napoleão em Portugal, em 1808. Revista jurídica, Lisboa, n. 2/3, p.103, 1985.

\section{6}

Sobre esta "súplica" (Anexo 1), v. HOMEM, António Pedro Barbas. Algumas notas sobre a introdução do Código Civil de Napoleão em Portugal, em 1808; MESOUITA, António Pedro. O pensamento politico português no século XIX, p. 38 ss.

\section{7}

Cf. "Estatuto Constitucional do Ducado de Varsóvia" (Anexo 2), Título I, paragráfos 1-3. Datado de 22.07.1807, em Le Moniteur, Paris, le 1er août, "Statut constitutionnel du Duché de Varsovie ". Publicado, em versão electrónica, em HESPANHA, António. M.; SILVA, Cristina Nogueira da. Fontes para a história constitucional portuguesa (c. 1800-1910). Lisboa: Faculdade de Direito da Universidade Nova de Lisboa, 2004, DVD (também em www.fd.unl.pt - "Biblioteca Virtual").

\section{8}

Cf. "Estatuto Constitucional do Ducado de Varsóvia", I, 4 (a abolição da escravatura, se não tinha relevo para o Reino, tê-lo-ia para as colônias; mas seguramente que os peticionários não tinham em mente um espaço tão vasto, tanto mais que o Brasil estava, tinha, nessa altura, um governo separado e dificilmente recuperável neste contexto).

19

Cf. "Estatuto Constitucional do Ducado de Varsóvia", IX, 69.

\section{0}

No "Estatuto Constitucional do Ducado de Varsóvia", um Senado e uma Câmara dos Deputados ("Chambre des Nonces").

\section{1}

No "Estatuto Constitucional do Ducado de Varsóvia", esta câmara era eleita pelas dietas distritais e pelas comunas (VI, 35).

\section{2}

Fórmula ambigua que podia significar várias coisas (Iniciativa legislativa? Atribuições legislativas autónomas). No "Estatuto Constitucional do Ducado de Varsóvia", II, 6; e III, 15, o significado era o primeiro: de reservar ao rei a iniciativa da proposição das leis.

23

"Estatuto Constitucional do Ducado de Varsóvia", II, 6 . a Espanha ${ }^{14}$. Se o Bispo de Coimbra não estava, na sua peça justificativa a encobrir um fato que se tornaria grave na perspectiva da Regência absoluta, reinstalada no trono, a alusão de José Acúrsio das Neves pode relacionar-se com alguma referência feita pelo Napoleão à necessidade de rever as instituições portuguesas, por pouco liberais.

Entretanto, Junot manobrava para se fazer lembrar como possível alternativa para o trono. Assim, suscita a formação de uma "Junta" em que, em torno de um núcleo de três deputados da Junta dos Três Estados - uma instituição criada depois da Restauração brigantina para gerir as contribuições militares, mas a que agora, juntamente com o Senado da Câmara de Lisboa, se reconhece alguma legitimidade "representativa" -, se agrupa mais uma série de deputados nomeados pelo general para representar o clero, a nobreza, a magistratura, a câmara e povo de Lisboa. A Junta endereça uma mensagem a Napoleão (24.5.1808) tentando promover a figura de Junot.

Em oposição a este projecto, mas também ao do retorno dos Bragança, um outro grupo - de que fariam parte o desembargador Francisco Duarte Coelho, o lente de direito Simão de Cordes Brandão e o reitor do Colégio dos Nobres, Ricardo Raimundo Nogueira, jurista cuja influência se irá manter nas décadas seguintes ${ }^{15}$ - induz o juiz do povo de Lisboa, José de Abreu Campos, a apresentar à Junta dos Três Estados uma "súplica" (redigida pelo doutor Gregório José de Seixas) dirigida a Napoleão, contendo as principais reivindicações politicas do reino. Nela se pede "uma constituição e um rei constitucional". Quanto a este último, precisava-se "que seja principe de sangue da vossa real família"16.

Quanto à constituição, a súplica de 1808 pedia "que fosse em tudo semelhante à que Vossa Majestade Imperial e Real houve por bem outorgar ao Grão-Ducado de Varsóvia, com a mínima diferença de que os representantes da nação sejam eleitos pelas câmaras municipais a fim de nos conformarmos com os nossos antigos usos".

Que constituição era esta, a de Varsóvia?

Os peticionários salientavam alguns dos seus traços. Do ponto de vista das relações entre o Estado e a Igreja, adoptar-se-ia uma religião de Estado - a católica apostólica -, com a adopção da concordata celebrada entre Napoleão e a Santa Sé que procurava resolver anteriores fontes de atrito entre os poderes espiritual e temporal; porém, era garantida a liberdade religiosa e de culto público ${ }^{17}$, uma solução que teria sido mais avançada do que aquela que iria dominar todo o periodo monárquico-constitucional. A igualdade perante a lei seria instituída, pondo fim aos privilégios estamentais e abolindo a escravatura ${ }^{18}$; o que se efectivaria, nomeadamente, pela proposta de adopção do Código de Napoleão ${ }^{19}$. Instituir-se-ia a separação dos três poderes. 0 legislativo estaria a cargo de duas câmaras 20 , cujos membros seriam eleitos, "de acordo com os nossos antigos usos e costumes", pelas câmaras municipais 21 , e que exerceria as suas funções "com a concorrência da autoridade legislativa" 22. 0 executivo cabia, no topo, ao rei 23 . Que, porém, no seu desempenho, seria assistido por um Conselho de Estado 24, composto por "ministros responsáveis", avançando-se aqui um princípio - o da responsabilidade ministerial - que, embora sempre presente no constitucionalismo subsequente, demonstrará ser uma sua verdadeira cruz 25. Na Constituição de Varsóvia, o Conselho de Estado (ministério) dirimiria os conflitos de competência entre jurisdição e administração, funcionando ainda como Cour de Cassation, como tribunal de contencioso administrativo e como foro especial dos agentes da administração. 
No "Estatuto Constitucional do Ducado de Varsóvia", III, 13, institui-se um regime "de gabinete", em que o rei nomeia um "presidente do conselho" - que escolhe os ministros - e em que os ministros reúnem e deliberam entre si, e não isoladamente com o rei. Em Portugal, esta solução apenas se efectivará em pleno cartismo e, mesmo então, apenas pela prática constitucional.

\section{5}

Também nesta matéria da responsabilidade ministerial, há ambiguidades (Responsabilidade politica ? Perante quem ? Responsabilidade jurídica ? Efectivada por que órgão ?). Cf. HESPANHA, António. M.. Guiando a mão invisivel. Direitos, Estado e lei no Constitucionalismo Monárquico português. Coimbra: Almedina, 2004.

\section{6}

O Code civil (ou Code Napoléon) vigorava como fonte subsidiária, nos termos dos Estatutos da Universidade de 1772, que mandavam aplicar directamente, em vastos domínios do direito, as leis das nações cultas e civilizadas da Europa. Durante a ocupação napoleónica (1807-1808), a promulgação do Code em Portugal esteve iminente. Cf. SILVA, Nuno E. Gomes da. História do direito português. Vol. I: Lisboa: Fundação Calouste Gulbenkian, 2006. p.483-485.

\section{7}

As colônias seriam transformadas em provincias ou distritos "fazendo parte integrante do reino" e dotadas de representação parlamentar ("para que seus representantes desde já designados, achem em a nossa organização social os lugares que thes pertencem, logo que venham ou possam vir ocupá-los").

\section{8}

Embora os excedentários "recebam sempre os ordenados, ou pelo menos uma proporcionada pensão, e que nas vacaturas tenham preferência a outros quaisquer".

29

Fora estabelecido nas Cortes de Tomar, em 1579; agora, voltava a justificar-se, em face da ameaça de nomeação de franceses para cargos portugueses.

30

Cf. "Estatuto Constitucional do Ducado de Varsóvia", IX, 74.

31

Ibidem, IX, 69.

32

Novidade em relação ao "Estatuto

Constitucional do Ducado de Varsóvia", III, 11.

\section{3}

0 modelo constitucional napoleônico tem sido objecto de recente revisão, nomeadamente no quadro de uma série de conferências subordinadas ao tema "Fremdherrschaft und Freiheit. Das Königreich Westphalen als napoleonischer "Modellstaat»", organizado pelo Fachbereich Geschichte, da Universidade de Kassel (v. programa em http://hsozkult.geschichte.hu-berin.de/termine/id=8001); v. ainda, o programa do Colloquium veranstaltet vom Zentrum für Historische Forschung Berlin der Polnischen Akademie der Wissenschaften (em http://www. ahf-muenchen.de/Veranstaltungskalender Vortragsreihen/Aktuell.htm).
No contexto português da época, a disposição mais revolucionária será, decerto, a adopção directa 26 do Code civil (1804), a qual viria abolir o regime senhorial da terra, introduzir o divórcio e modificar alguns pontos fundamentais do direito sobre as coisas, nomeadamente do direito agrário.

Quanto aos níveis administrativos do executivo, enfatiza-se a necessidade de reforma da administração e do funcionalismo. A administração seria objecto de uma reforma de cunho racionalizador, segundo o modelo francês (nomeadamente, fazendo coincidir as divisões civis com as eclesiásticas) ${ }^{27}$. 0 número de funcionários devia diminuir 28 , prevendo-se ainda a reafirmação do principio do indigenato no provimento dos cargos públicos ${ }^{29}$, combinado com a adopção do sistema do mérito ("que melhor os [empregos] merecerem"). Consagrava-se a independência do poder judicial 30 , melhorando o seu funcionamento ("sentenças proferidas com justiça, publicidade e prontidão"), objectivo que aparece ligado à já referida adopção do Código de Napoleão 31. Previa-se um especial cuidado com a instrução pública, criando um ministério próprio para tal fim 32 ; instituia-se a liberdade de imprensa; pediam-se medidas de desamortização, a proporcionalidade dos impostos e a consolidação e garantia da dívida pública.

0 confronto entre estas linhas gerais da petição e o texto constitucional escolhido como modelo suscita algumas reflexões 33 .

Desde logo, a da escolha de um modelo tão inusitado como a de um pais do outro extremo da Europa e com uma tradição completamente alheia ao cânone constitucional europeu ocidental. Na realidade, a Constituição do Grão-Ducado de Varsóvia 34 era, então, a mais recente das constituições dos Estados satélites da França napoleónica, todas elas inspiradas na Constituição francesa do Ano VIII (13.12.1799) ${ }^{35}$; sendo essa, porventura, a causa determinante da escolha. Para mais, o facto de se ter escolhido como modelo um Estado com dignidade abaixo da real - um grão-ducado - visava ainda simbolizar o futuro estatuto de Portugal no concerto das nações da Europa.

No entanto, apesar da discrição e indefinição do pedido, afloram alguns elementos de especificidade. Embora o texto apenas refira uma modificação a introduzir no modelo ("com a única diferença"), relativa ao modo de eleição dos "representantes da Nação", a súplica refere questões especificamente portuguesas e não contempladas na constituição polaca. Uma delas é a integração das colônias no reino, compreensivelmente ausente da constituição de um Estado sem colônias. Outra, a reforma da administração e do funcionalismo, a apontar para uma sensibilidade quanto ao desgoverno administrativo que se manterá muito duradouramente e cuja efectividade e causas será oportuno investigar. Os outros pedidos específicos parece apontarem, ou para questões conjunturais muito sentidas (como a da dívida pública, cuja consolidação ${ }^{36}$ se pedia), ou para uma ideia reformista mais avançada em Portugal do que num país menos laicizado e mais senhorializado, como a Polônia: é o que se passa quanto à promoção da instrução pública, a exigir a criação de um ministério próprio, à liberdade de imprensa, à desamortização e à igualdade dos impostos.

0 projecto de súplica não teve seguimento, desde logo por não se adequar à política pessoal de Junot, mas é revelador das ideias constitucionalistas no princípio do século XIX, até pela presença de Ricardo Raimundo Nogueira - um ativíssimo propugnador de ideias constitucionais moderadas 
Formado em 1807, depois da derrota da Prússia, com territórios situados em torno de Varsóvia e Poznan, e posto sob a hegemonia do rei do Saxe.

\section{5}

1801 (14.09), Constituição da República da Batávia, convertida no reino da Holanda em 1806; 1801 (07.10), Constituição da República Cisalpina; 1801 (26.12), Constituição da República de Lucca; 1802 (06.02), Constituição da República Italiana (convertida em Reino de Itália em 1805); 1802, Constituição da República Ligure; 1805 (24.06), Estatuto constitucional do Estado de Lucca. A Constituição de Baiona só surgirá em 6.7.1808, prevendo ainda uma aplicação gradual, que apenas culminava, com a reunião de cortes, em 1820. A Confederação Renana - constituida em 1806 e a que adere a quase totalidade dos estados do antigo Império Alemão - não tem uma constituição.

36

Ou seja, a sua conversão em títulos com um rendimento certo e periódico a favor dos credores.

\section{7}

"Memórias sabre as cousas mais notáveis que se trataram nas conferencias de governo d'estes reinos" (códices 6848 a 6053 da Biblioteca Nacional de Lisboa, Seção de Reservados). até aos finais dos anos 20 - no grupo que inspirou o documento. De qualquer modo, também mais tarde não poderia ter seguimento, em virtude da forte reacção anti-francesa que dominava, após a expulsão dos exércitos de Massena. Afinal, a Constituição do Grão-Ducado de Varsóvia não deixava de se integrar na série de constituições dadas aos Estados satélites do Império francês. Em todo o caso, a leitura de um diário das sessões da Junta de Governo, existentes na Biblioteca Nacional de Lisboa 37, indica que idéias proto-liberais existiam mesmo no estreito círculo de governo em Lisboa, de que fariam parte elementos ligados a lojas maçônicas, com activos contactos fora do pais.

\section{Anexos}

\section{Súplica dirigida a Napoleão, em 24.05.1807, pela Junta dos Três Estados.}

"Lembrando-se os portugueses que são de raça francesa como descendentes que conquistaram este belo país aos mouros em 1147, e que devem à França sua mãe pátria o benefício da independência, que recobraram como Nação em 1640, solícitos recorrem, cheios de respeito, à paternal protecção, que o maior dos monarcas há por bem outorgar-Ihes Dignando-se o imortal Napoleão patentear-nos a sua vontade por órgão dos nossos deputados, quer que sejamos livres, e que nos liguemos com indissolúveis laços ao sistema continental da família europeia; quer que as nações, que compõem esta grande família vivam unidas, e que prestes possam gozar das delícias de uma prolongada paz à sombra de sábios governos, fundados nas grandes bases da legislação e da liberdade marítima e comercial, É portanto do nosso peculiar interesse, assim como dos outros povos confederados que a nossa deputação continue a ser junto de sua majestade imperial e real o interprete dos nossos unânimes votos, e que the diga

"Senhor! - Desejamos ser ainda mais do que éramos, quando abrimos o oceano a todo o universo. Pedimos uma constituição e um rei constitucional que seja príncipe de sangue da vossa real familia Dar-nos-emos por felizes se tivermos uma constituição em tudo semelhante á que vossa majestade imperial e real houve por bem outorgar ao grão-ducado de Varsóvia, com a mínima diferença de que os representantes da nação sejam eleitos pelas câmaras municipais a fim de nos conformarmos com os nossos antigos usos. Queremos uma constituição na qual, à semelhança da de Varsóvia, a religião católica apostólica romana seja a religião do Estado; em que sejam admitidos os princípios da última concordata entre o império francês e a santa Sé pela qual sejam livres todos os cultos, e gozem da tolerância civil e de exercício publico. Em que todos os cidadãos sejam iguais perante a lei. Em que o nosso território europeu seja dividido em oito províncias, assim a respeito da jurisdição eclesiástica como da civil, de maneira que só fique havendo um arcebispo e sete bispos. Em que as nossas colônias fundadas por nossos avós, e com o seu sangue banhadas, sejam consideradas como provincias ou distritos fazendo parte integrante do reino para que seus representantes desde já designados, achem em a nossa organização social os lugares que thes pertencem, logo que venham ou possam vir ocupá-los. Em que haja um ministério especial para dirigir e inspeccionar a instrução publica. Em que seja livre a imprensa porquanto a ignorância e o erro tem originado a nossa decadência Em que poder execu- 
tivo seja assistido das luzes de que Conselho de Estado, e não possa obrar senão por meio de ministros responsáveis. Em que o poder legislativo seja exercido por duas câmaras com a concorrência da autoridade executiva. Em que o poder judicial seja independente, o código de Napoleão posto em vigor, e as sentenças proferidas com justiça, publicidade e prontidão Em que os empregos públicos sejam exclusivamente exercidos pelos nacionais que melhor os merecerem, conforme o que se acha determinado no artigo $2^{\circ} \mathrm{da}$ constituição polaca. Em que os bens de mão morta sejam postos em circulação. Em que os impostos sejam repartidos, segundo as posses e fortuna de cada um, sem excepção alguma de pessoa ou classe, e da maneira que mais fácil e menos opressiva for para os contribuintes, Em que toda a divida pública se consolide e garanta completamente visto haver recursos para Ihe fazer face. Queremos igualmente que a organização pessoal da administração civil, fiscal e judicial seja conforme o sistema francês e que por conseguinte se reduza o numero imenso dos nossos funcionários públicos mas desejamos e pedimos que todos os empregados que ficarem fora dos seus quadros recebam sempre os ordenados, ou pelo menos uma proporcionada pensão, e que nas vacaturas tenham preferência a outros quaisquer. Era sem duvida inútil lembrar esta medida de equidade ao grande Napoleão; mas como sua majestade imperial e real quer conhecer a nossa opinião em tudo o que nos convém, evidentemente nos prova que é mais pai do que soberano nosso, dignando-se consultar seus filhos e prestar-Ihes os meios para serem felizes. - Viva o imperador».

(De acordo com a versão publicada por Simão José Luz Soriano, Historia da guerra civil e do governo parlamentar, Segunda Época, I, p. 212-214).

2. Estatuto Constitucional do Ducado de Varsóvia (Le Moniteur, Paris, $1^{\circ}$ de Agosto).

[tradução: Márcia Valéria Martinez de Aguiar]

\section{TÍTULO I}

Art. $1^{\circ}$. A religião católica, apostólica e romana é a religião do Estado.

Art. $2^{\circ}$. Todos os cultos são livres e públicos.

Art. $3^{\circ} .0$ ducado de Varsóvia será dividido em seis dioceses; haverá um arcebispo e cinco bispos.

Art. $4^{\circ}$. Fica abolida a escravidão; todos os cidadãos são iguais perante a lei; o estado das pessoas está sob a proteção dos tribunais.

\section{TíTULO II.}

Do governo.

Art. 5․ A coroa ducal de Varsóvia é hereditária na pessoa do rei de Saxe, seus descendentes, herdeiros e sucessores, segundo a ordem de sucessão estabelecida na Casa de Saxe.

Art. $6^{\circ} .0$ governo reside na pessoa do rei.

Ele exerce em toda sua plenitude as funções do poder executivo.

Ele tem a iniciativa das leis.

Art. $7^{\circ} .0$ rei pode delegar a um vice-rei a porção de sua autoridade que não julgar oportuno exercer imediatamente.

Art. $8^{\circ}$. Se o rei não julgar oportuno nomear um vice-rei, ele nomeará um presidente do conselho de ministros. 
Membro do conselho encarregado de apresentar, com voz deliberativa, relatórios sobre os assuntos que lhe são submetidos. É um cargo prestigioso na administração, estando somente abaixo do conselheiro de Estado. (N. T.).
Neste caso, os assuntos dos diferentes ministérios serão discutidos no conselho, para serem apresentados à aprovação do rei.

Art. $9^{\circ}$. 0 rei convoca, prorroga ou adia a assembléia da dieta geral.

Ele convoca igualmente as dietinas ou assembléias distritais e as assembléias comunais.

Ele preside o senado quando julgar conveniente.

Art. $10^{\circ}$. Os bens da coroa ducal consistem: $1^{\circ}$ de uma renda anual de sete milhões de florins da Polônia, metade em terras ou domínios reais, metade em uma afetação do tesouro público; $2^{\circ}$ do Palácio Real de Varsóvia e do Palácio de Saxe.

\section{TÍTULO III}

Dos Ministros e do Conselho de Estado

Art. 11\%. 0 ministério é composto como se segue:

Um ministro da justiça,

Um ministro do interior e dos cultos.

Um ministro da guerra.

Um ministro das finanças e do tesouro,

Um ministro da polícia.

Há um ministro secretário de Estado.

Os ministros são responsáveis.

Art. $12^{\circ}$. Quando o rei julgar conveniente transmitir a um vice-rei a porção de sua autoridade que não reservou imediatamente para si próprio, cada um dos ministros trabalhará separadamente com o vice-rei

Art. $13^{\circ}$. Quando o rei não houver nomeado um vice-rei, os ministros se reunirão em conselho de ministros, conforme o que foi dito acima, Art. $8^{\circ}$.

Art. 14․ 0 Conselho de Estado é composto pelos ministros, pelo vicerei ou pelo presidente nomeado pelo rei.

Art. $15^{\circ}$. 0 Conselho de Estado discute, redige e estabelece os projetos de lei ou os regulamentos da administração pública, que são propostos por cada ministro com relação aos objetos de seus respectivos departamentos.

Art. $16^{\circ}$. Quatro maîtres des requêtes ${ }^{38}$ [procuradores] estão ligados ao Conselho de Estado, seja para a instrução dos assuntos administrativos e para aqueles em que o Conselho se pronuncia como Corte de cassação, seja para as comunicações do Conselho com as comissões da Câmara dos núncios.

Art. $17^{\circ}$. Ao Conselho de Estado cabe julgar os conflitos de jurisdição entre os corpos administrativos e os corpos judiciários, as contendas da administração e, se for o caso, os agentes da administração pública.

Art. $18^{\circ}$. As decisões, projetos de lei, decretos e regulamentos discutidos no Conselho de Estado, são submetidos à aprovação do rei.

\section{TÍTULO IV}

\section{Da Dieta geral.}

Art. $19^{\circ}$ : A dieta geral é composta de duas câmaras, a saber: a la câmara ou câmara do senado; a 2a câmara, ou câmara dos núncios.

Art. 20․ A dieta geral se reúne, a cada dois anos, em Varsóvia, na época fixada pelo ato de convocação emanando do rei.

A sessão não deverá durar mais de quinze dias.

Art. $21^{\circ}$. Suas atribuições consistem na deliberação da lei das taxações, ou lei das finanças, e das leis relativas às mudanças a serem feitas, seja na legislação civil, seja na legislação criminal, seja no sistema monetário. 
Art. $22^{\circ}$. Os projetos de leis redigidos no Conselho de Estado são transmitidos à dieta geral por ordem do rei, deliberados na câmara dos núncios por escrutínio secreto e por pluralidade dos sufrágios, e apresentados à sanção do Senado.

\section{TíTULO V}

\section{Do Senado.}

Art. $23^{\circ} .0$ senado é composto por dezoito membros, a saber:

Seis bispos;

Seis palatinos;

Seis castelões.

Art. $24^{\circ}$. Os palatinos e os castelões são nomeados pelo rei.

Os bispos são nomeados pelo rei e instituídos pela Santa Sé.

Art. $25^{\circ}$. 0 senado é presidido por um de seus membros, nomeado para esse efeito pelo rei.

Art. $26^{\circ}$. As funções dos senadores são vitalícias.

Art. $27^{\circ}$. Os projetos de leis deliberados na câmara dos núncios, conforme ao que é dito mais abaixo, são transmitidos à sanção do senado.

Art. 28․ 0 senado dá sua aprovação à lei, a não ser nos seguintes casos:

lo Quando a lei não tiver sido deliberada nas formas prescritas pela constituição, ou quando a deliberação houver sido perturbada por atos de violência;

$2^{\circ}$ Quando for de seu conhecimento que a lei não foi adotada pela maioria dos votos;

$3^{\circ}$ Quando o senado julgar que a lei é contrária à segurança do Estado, ou às disposições do presente estatuto constitucional.

Art. $29^{\circ}$. No caso de o senado recusar, por um dos motivos acima, sua sanção a uma lei, ele investirá o rei, por uma deliberação motivada, da autoridade necessária para anular a deliberação dos núncios.

Art. $30^{\circ}$. Quando a recusa do senado for motivada por um dos dois primeiros casos previstos pelo art. 28, o rei ordenará a devolução do projeto à câmara dos núncios, com a injunção de proceder com regularidade. Se as mesmas desordens se repetirem, seja no comportamento da assembléia, seja nas formas de deliberação, a câmara dos núncios será por esse motivo dissolvida, e o rei ordenará novas eleições.

Art. $31^{\circ}$. No caso da dissolução da câmara dos núncios, a lei das finanças será prorrogada por um ano, e as leis civis ou criminais continuarão em vigor sem modificação ou mudança.

Art. $32^{\circ}$. Quando o senado recusar sancionar uma lei, o rei poderá igualmente, e em todos os casos, nomear novos senadores e enviar novamente a lei ao senado.

Contudo, o senado não pode se ver composto de mais de seis bispos, doze palatinos e doze castelões.

Art. $33^{\circ}$. Quando o rei usar o direito estabelecido pelo artigo acima, os lugares que vierem a vagar no senado entre os palatinos e os castelões não serão preenchidos até que o senado seja reduzido ao número fixado pelo art. 23.

Art. $34^{\circ}$. Quando o senado tiver dado sua aprovação a uma lei, ou que o rei, não obstante os motivos da deliberação do senado, tiver ordenado sua promulgação, o projeto será declarado lei e imediatamente obrigatório. 


\section{TíTULO VI.}

\section{Da câmara dos núncios}

Art. $35^{\circ}$. A câmara dos núncios é composta:

10 De sessenta núncios nomeados pelas dietinas ou assembléias dos nobres de cada distrito, à razão de um núncio por distrito.

Os núncios devem ter no mínimo 24 anos completos, gozar de seus direitos ou serem emancipados.

$2^{\circ}$ De quarenta deputados das comunas.

Art. $36^{\circ}$. Todo o território do ducado de Varsóvia é dividido em quarenta assembléias comunais, a saber: oito para a cidade de Varsóvia, e trinta e duas para o resto do território.

Art. $37^{\circ}$. Cada assembléia comunal deve compreender no mínimo seiscentos cidadãos com direito de votar.

Art. $38^{\circ}$. Os membros da câmara dos núncios permanecem na função durante nove anos. A cada três anos, um terço da câmara é renovado.

Conseqüentemente, e unicamente na primeira vez, um terço dos membros da câmara dos núncios permanecerá na função somente durante três anos, e um outro terço durante seis anos.

A lista dos membros que sairão nessas duas ocasiões será escolhido por sorteio.

Art. $39^{\circ}$. A câmara dos núncios é presidida por um marechal escolhido entre seus pares e nomeado pelo rei.

Art. $40^{\circ}$. A câmara dos núncios delibera sobre os projetos de leis, que são em seguida transmitidos à sanção do senado.

Art. $41^{\circ}$. Ela nomeia em cada sessão, por escrutínio secreto e por maioria dos sufrágios, três comissões compostas cada uma por cinco membros, a saber:

Comissão das finanças;

Comissão de legislação civil;

Comissão de legislação criminal.

0 marechal presidente da câmara dos núncios comunica ao Conselho de Estado, por uma mensagem, a nomeação das ditas comissões.

Art. $42^{\circ}$. Quando um projeto de lei foi redigido no Conselho de Estado, ele é comunicado à comissão à qual seu objeto concerne, pelo ministro do departamento ao qual este objeto é relativo, e por intermédio dos mâitres des requêtes [procuradores] ligados ao Conselho de Estado.

Se a comissão tiver observações a fazer sobre o projeto de lei, ela se reunirá no gabinete do dito ministro. Os maîtres de requêtes [procuradores] encarregados da comunicação do projeto de lei serão admitidos nessas conferências.

Art. $43^{\circ}$. Se a comissão persistir nas suas observações, e requisitar modificações no projeto de lei, isso será relatado pelo ministro ao Conselho de Estado.

0 Conselho de Estado pode admitir, em seu seio, os membros da comissão, para discutir as disposições do projeto de lei que pareceram suscetíveis de modificações

Art. 44․ 0 Conselho de Estado tendo tomado conhecimento das observações da comissão, seja pelo relatório do ministro, seja pela discussão havida em seu seio, fixa definitivamente a redação do projeto de lei, que é transmitido à câmara dos núncios para ser deliberado.

Art. 45․ Os membros do Conselho de Estado são membros natos da câmara dos núncios. Participam das sessões e têm voz deliberativa. 
Art. 46․ Os membros do Conselho de Estado e os membros da comissão dos núncios são os únicos a ter o direito de fala na câmara, seja no caso de o conselho e a comissão estarem de acordo sobre o projeto de lei, para ressaltar-Ihe as vantagens, seja no caso de dissentimento para ressaltar ou combater-Ihe os inconvenientes.

Nenhum outro membro pode tomar a palavra sobre o projeto de lei.

Art. $47^{\circ}$. Os membros da comissão podem manifestar sua opinião individual sobre o projeto de lei, tanto se houverem concordado com a opinião da maioria da comissão, quanto se sua opinião tiver sido a da minoria.

Os membros do Conselho de Estado, ao contrário, só podem falar em favor do projeto de lei estabelecido no Conselho.

Art. 48․ Quando o marechal-presidente da câmara dos núncios julgar que a matéria estiver suficientemente esclarecida, ele poderá encerrar a discussão e colocar o projeto de lei em deliberação.

A câmara delibera em escrutínio secreto e por maioria absoluta dos sufrágios.

Art. 49․ A lei tendo sido deliberada, a câmara dos núncios a transmite imediatamente ao senado.

\section{TITULO VII.}

Das Dietinas e Assembléias comunais.

Art. $50^{\circ}$. As dietinas, ou assembléias de distrito, são compostas pelos nobres do distrito.

Art. $51^{\circ}$. As assembléias comunais são compostas pelos cidadãos proprietários não nobres, e por outros cidadãos que poderão fazer parte dela, como será dito abaixo:

Art. $52^{\circ}$. As dietinas e as assembléias comunais são convocadas pelo rei. 0 lugar, o dia de sua reunião, as operações às quais devem proceder assim como a duração da sessão, são exprimidas nas cartas de convocação.

Art. $53^{\circ}$. Ninguém pode ser admitido para votar se não tiver a idade de vinte e um anos completos, se não gozar de seus direitos ou não for emancipado. A emancipação poderá contudo ser concedida aos vinte e um anos, não obstante todas as leis e usos contrários.

Art. 54․ Cada dietina, ou assembléia de distrito nomeia um núncio, e apresenta candidatos para os conselhos de departamento e de distrito, e para as justiças de paz.

Art. $55^{\circ}$. As dietinas são presididas por um marechal nomeado pelo rei.

Art. $56^{\circ}$. Elas são divididas em dez séries. Cada série é composta de distritos separados uns dos outros pelos territórios de um ou vários distritos. Duas séries não podem ser convocadas ao mesmo tempo.

Art. $57^{\circ}$. Os deputados das comunas são nomeados pelas assembléias comunais.

Elas apresentam uma lista dupla de candidatos para os conselhos municipais.

Art. $58^{\circ}$. Têm direito a votar nas assembléias comunais;

10 Todo cidadão proprietário não nobre;

$2^{\circ}$ Todo fabricante e chefe de oficina, todo mercador que tenha um comércio ou uma loja equivalente a um capital de 10.000 florins de Bolonha;

$3^{\circ}$ Todos os curas e vicários;

$4^{\circ}$ Todo artista, e cidadão que se distinguir por seus talentos; seus conhecimentos, ou pelos serviços prestados, seja ao comércio, seja às artes;

$5^{\circ}$ Todo sub-oficial e soldado que, tendo sido ferido ou feito várias campanhas, tiver obtido sua aposentadoria; 
$6^{\circ}$ Todo sub-oficial e soldado em atividade de serviço que tenha obtido distinções por sua boa conduta;

$7^{\circ}$ Os oficiais de qualquer grau.

Os citados oficiais, sub-oficiais e soldados, atualmente em atividade de serviço que se encontrarem de guarnição na cidade em que a assembléia comunal estiver reunida, não poderão gozar, apenas neste caso, do direito concedido pelo presente artigo.

Art. 59 ${ }^{\circ}$. A lista dos votantes proprietários é estabelecida pela municipalidade, e certificada pelos recebedores das contribuições.

A dos curas e vicários é estabelecida pelo prefeito, e ratificada pelo ministro do interior.

A dos oficiais, sub-oficiais, soldados, designados no artigo acima, é estabelecida pelo prefeito, e ratificada pelo ministro da guerra.

A dos fabricantes e chefes de oficina e dos mercadores que tenham um comércio, loja ou estabelecimentos de fábrica com um capital de dez mil florins da Polônia, e a dos cidadãos que se distinguem por seus talentos, conhecimentos e serviços prestados seja às ciências e às artes, seja ao comércio, são estabelecidas pelo prefeito e ratificadas todo ano pelo senado.

Os cidadãos que se encontram no último dos casos aqui enunciados, podem dirigir suas petições diretamente ao senado, com os documentos justificativos de seus pedidos.

Art. $60^{\circ} .0$ senado, em todos os casos em que houver motivos para se suspeitar de abusos na formação das listas, pode ordenar que sejam feitas novas.

Art. $61^{\circ}$. As assembléias comunais não podem ser convocadas ao mesmo tempo, em toda a extensão de um distrito. Haverá sempre um intervalo de oito dias entre a reunião de cada uma delas, exceto, contudo, no que se refere às da cidade de Varsóvia, que podem ser convocadas ao mesmo tempo, mas apenas no número de duas.

Art. $62^{\circ}$. As assembléias comunais são presididas por um cidadão nomeado pelo rei.

Art. $63^{\circ}$. Não poderá haver, nas dietinas ou nas assembléias comunais, qualquer discussão de qualquer natureza que possa ser, qualquer deliberação, petição ou súplica ao rei.

Elas devem tratar apenas da eleição, seja dos deputados, seja dos candidatos, cujo número é designado com antecedência, como está dito acima, pelas cartas de convocação.

\section{TíTULO VIII}

Divisão do território e administração

Art. 64. 0 território permanece dividido em seis departamentos.

Art. $65^{\circ}$. Cada departamento é administrado por um prefeito.

Há, em cada departamento, um conselho para assuntos contenciosos, composto de três membros no mínimo e de cinco no máximo, e um conselho geral de departamento, composto de dezesseis membros, no mínimo, e de vinte e quatro, no máximo.

Art. $66^{\circ}$. Os distritos são administrados por um sub-prefeito.

Há em cada distrito um conselho distrital composto por nove membros, no mínimo, e de doze, no máximo.

Art. $67^{\circ}$. Cada municipalidade é administrada por um prefeito municipal ou presidente;

Há, em cada municipalidade, um conselho municipal, composto de dez membros para dois mil e quinhentos habitantes ou menos; de vinte para 
cinco mil habitantes ou menos; e de 15 para as cidades cuja população exceda cinco mil habitantes.

Art. $68^{\circ}$. Os prefeitos, conselheiros de prefeitura, sub-prefeitos e prefeitos municipais, são nomeados pelo rei, após apresentação prévia.

Os membros dos conselhos de departamentos, e dos conselhos distritais são nomeados pelo rei, a partir de uma lista dupla de candidatos apresentados pelas dietinas de distrito. A cada dois anos, são renovados metade de seus membros.

Os membros dos conselhos municipais são nomeados pelo rei, a partir de uma lista dupla de candidatos apresentados pelas assembléias comunais.

A cada dois anos são renovados metade de seus membros.

Os conselhos de departamento e de distrito, e os conselhos municipais, nomeiam um presidente escolhido entre seus pares.

\section{TíTULO IX.}

Ordem Judiciária

Art. 69 $9^{\circ} 0$ Código Napoleônico constituirá a lei civil do ducado de Varsóvia

Art. $70^{\circ}$. 0 processo é público em matéria civil e criminal.

Art. $71^{\circ}$. Há uma justiça de paz por distrito;

Um tribunal civil de primeira instância por departamento;

Uma corte de justiça criminal para dois departamentos;

Uma única corte de apelação para todo o ducado de Varsóvia.

Art. $72^{\circ}$. 0 Conselho de Estado, ao qual devem se juntar quatro maîtres de rêquetes [procuradores] nomeados pela lei, exerce as funções de corte de cassação.

Art. $73^{\circ}$. Os juizes de paz são nomeados pelo rei a partir de uma lista tríplice de candidatos apresentados pelas dietinas de distritos. A cada dois anos, um terço deles é renovado.

Art. $74^{\circ}$. A ordem judiciária é independente.

Art. $75^{\circ}$. Os juizes dos tribunais de primeira instância, das cortes criminais e das cortes de apelação, são nomeados pelo rei vitaliciamente.

Art. $76^{\circ}$. A corte de apelação pode, seja a partir da denúncia do procurador real, seja a partir da denúncia de um de seus presidentes, pedir ao rei a destituição de um juiz de um tribunal de primeira instância ou de uma corte criminal que ela acreditar culpada de prevaricação no exercício de suas funções.

A destituição de um juiz da corte de apelação pode ser pedida pelo Conselho de Estado, exercendo as funções de corte de cassação.

Apenas nesses casos, a destituição de um juiz pode ser pronunciada pelo rei.

Art. $77^{\circ}$. Os julgamentos das cortes e dos tribunais são feitos em nome do rei.

Art. $78^{\circ} .0$ direito de conceder graça pertence ao rei; apenas ele pode perdoar ou comutar a pena.

\section{TítULO X}

\section{Das forças armadas}

Art. $79^{\circ}$. As forças armadas serão compostas de 30.000 homens de todas as armas, efetivamente servindo, excluindo-se as guardas nacionais.

Art. $80^{\circ} .0$ rei poderá chamar para Saxe uma parte das tropas do ducado de Varsóvia, substituindo-as por igual número de tropas saxônicas. 
Art. $81^{\circ}$. No caso de as circunstâncias exigirem que, independentemente das tropas do ducado de Varsóvia, o rei envie para o território desse ducado outros corpos de tropas saxônicos, não poderia ser estabelecido nesta ocasião nenhum outro tributo ou encargo público que já não tivessem sido autorizados pela lei das finanças.

\section{TÍTULO XI}

\section{Disposições gerais}

Art. $82^{\circ}$. Os titulares de todos os cargos e funções que não são vitalícios, inclusive a vice-realeza, são revogáveis segundo a vontade do rei, com exceção dos núncios.

Art. 83․ Nenhum indivíduo, se não for cidadão do ducado de Varsóvia, pode ser chamado a aí exercer nenhuma função, seja eclesiástica, seja civil, seja judiciária.

Art. 84. Todos os atos do governo, da legislação, da administração e dos tribunais serão escritos em língua nacional.

Art. $85^{\circ}$. As Ordens civis e militares precedentemente existentes na Polônia são mantidas. 0 rei é o chefe dessas Ordens.

Art. $86^{\circ} .0$ presente Estatuto constitucional será completado por regulamentos emanados do rei e discutidos em seu Conselho de Estado.

Art. $87^{\circ}$. As leis e regulamentos da administração pública serão publicados no Boletim das leis, e não precisam de outra forma de publicação para se tornarem obrigatórias.

\section{TíTULO XII}

\section{Disposições transitórias}

Art. $88^{\circ}$. As tributações atualmente existentes, continuarão a ser recebidas até 1ode janeiro de1809.

Art. $89^{\circ}$. Nada será mudado na quantidade e na organização atuais das tropas, até que a primeira dieta geral a ser convocada estatua sobre esse assunto.

Os membros da comissão de governo,

\section{Assinado,}

MALACKOWSKI, presidente ; GUTACKOWSKI, STANISLAS POTOCKI, DZIALINTSKI, WIBICKI, BILINSKI, SOBOLEWSKI, LUSZCREWSKI, secretário-geral.

NAPOLEÃO, pela graça de Deus e das constituições, imperador dos franceses, rei da itália, protetor da confederação do reno; nós aprovamos e continuamos a aprovar o Estatuto Constitucional acima, que nos foi apresentado como execução do artigo $V$ do tratado de Tilsitt, e que nós consideramos como apropriado para cumprir nossos compromissos para com os povos de Varsóvia e da Grande Polônia, conciliando suas liberdades e privilégios com a tranqüilidade dos Estados vizinhos.

Apresentado no Palácio Real de Dresden, em 22 de julho de 1807.

Assinado, NAPOLEÃO.

Pelo Imperador,

0 ministro secretário de Estado

Assinado, H. B. Maret. 
Statut Constitutionnel du Duché De Varsovie (Le Moniteur, Paris, le 1er août)

[documento original em francês]

\section{TITRE I} de l'État.

Art. 1er. La religion catholique, apostolique et romaine est la religion

II. Tous les cultes sont libres et publics.

III. Le duché de Varsovie sera divisé en six diocèses; i y aura un archevêché et cinq évêchés.

IV. L'esclavage est aboli; tous les citoyens sont égaux devant la loi ; l'état des personnes est sous la protection des tribunaux.

\section{TITRE II.}

Du Gouvernement.

Art. V. La couronne ducale de Varsovie est héréditaire dans la personne du roi de Saxe, ses descendons, héritiers et successeurs, suivant l'ordre de succession établi dans la Maison de Saxe.

VI. Le gouvernement réside dans la personne du roi.

II exerce dans toute sa plénitude les fonctions du pouvoir exécutif.

Il a l'initiative des lois.

VII. Le roi peut déléguer à un vice-roi, la portion de son autorité qu'il ne jugera pas à propos d'exercer immédiatement.

VIII. Si le roi ne juge pas à propos de nommer un vice-roi, il nomme un président du conseil des ministres.

Dans ce cas, les affaires des différents ministères sont discutées dans le conseil, pour être présentées à l'approbation du roi.

IX. Le roi convoque, proroge et ajourne l'assemblé de la diète générale.

Il convoque également les diétines ou assemblées de district et les assemblées communales.

II préside le sénat lorsqu'il le juge convenable.

$X$. Les biens de la couronne ducale consistent ; $1^{\circ}$ dans un revenu annuel de sept millions de florins de Pologne, moitié en terres ou domaines royaux, moitié en une affectation sur le trésor public ; $2^{\circ}$ dans le Palais Royal de Varsovie et le Palais de Saxe.

\section{TITRE III}

Des Ministres et du Conseil-d'État.

Art. XI. Le ministère est composé comme il suit :

Un ministre de la justice,

Un ministre de l'intérieur et des cultes,

Un ministre de la guerre,

Un ministre des finances et du trésor,

Un ministre de la police.

II y a un ministre sécretaire-d'État.

Les ministres sont responsables.

XII. Lorsque le roi a jugé à propos de transmettre à un vice-roi la portion de son autorité qu'il ne s'est pas immédiatement réservée, les ministres travaillent chacun séparément avec le vice-roi.

XIII. Lorsque le roi n'a pas nommé de vice-roi, les ministres se réunissent en conseil des ministres, conformément à ce qui a été dit ci - dessus, art. VIII. 
XIV. Le Conseil-d'État se compose des ministres, vice-roi, ou du président nommé par le roi.

XV. le Conseil-d'État discute, rédige et arrête les projets de loi ou les règlements d'administration publique, qui sont proposés par chaque ministre pour les objets relatifs à leurs départements respectifs.

XVI. Quatre maîtres des requêtes sont attachés au Conseil-d'État, soit pour l'instruction des affaires administratives et de celles dans lesquelles le conseil prononce comme cour de cassation, soit pour les communications du conseil avec les commissions de la chambre des nonces.

XVII. Le Conseil-d'État connaît des conflits de juridiction entre les corps administratifs et les corps judiciaires, du contentieux de l'administration, et de la mise en jugement des agents de l'administration publique.

XVIII. Les décisions, projets de loi, décrets et règlements discutés au Conseil-d'État, sont soumis à l'approbation du roi.

\section{TITRE IV}

De la Diète générale.

Art. XIX : La diète générale est composée de deux chambres, savoir : la lere chambre ou chambre du sénat; la 2eme chambre, ou chambre des nonces.

$X X$. La diète générale se réunit, tous les deux ans, à Varsovie, à l'époque fixée par l'acte de convocation émané du roi.

La session ne dure pas plus de quinze jours.

XXI. Ses attributions consistent dans la délibération de la loi des impositions, ou loi des finances et des lois relatives aux changements à faire, soit à la législation civile, soit à législation criminelle, soit au système monétaire.

XXII. Les projets de lois rédigés au Conseil d'État sont transmis à la diète générale par ordre du roi, délibérés à la chambre des nonces au scrutin secret et à la pluralité des suffrages, et présentés à la sanction du Sénat.

\section{TITRE V}

Du Sénat.

Art. XXIII. Le sénat est composé de dix-huit membres, savoir :

Six évêques ;

Six palatins :

Six castellans.

XXIV. Les palatins et les castellans sont nommés par le roi.

Les évêques sont nommés par le roi et institués par le Saint-Siége.

$X X V$. Le sénat est présidé par un de ses membres nommé à cet effet par le roi.

$X X V I$. Les fonctions des sénateurs sont à vie.

XXVII. Les projets de lois délibérés à la chambre des nonces, conformément à ce qui est dit ci-après, sont transmis à la sanction du sénat.

XXVIII. Le sénat donne son approbation à la loi, si ce n'est dans les cas ci-après:

10 Lorsque la loi n'a pas été délibérée dans les formes prescrites par la constitution, ou que la délibération aura été troublée par des actes de violence :

$2^{\circ}$ Lorsqu'il est à sa connaissance que la loi n'a pas été adoptée par la majorité des voix ;

$3^{\circ}$ Lorsque le sénat juge que la loi est contraire ou à la sûreté de l'État, ou aux dispositions du présent statut constitutionnel. 
XXIX. Dans le cas où par l'un des motifs ci-dessus, le sénat a refusé sa sanction à une loi, il investit le roi, par une délibération motivée, de l'autorité nécessaire pour annuler la délibération des nonces.

XXX. Lorsque le refus du sénat est motivé par l'un des deux premiers cas prévus par l'art. XXVIII, le roi, après ordonner le renvoi du projet de loi à la chambre des nonces, avec injonction de procéder avec régularité. Si les mêmes désordres se renouvellent, soit dans la tenue de l'assemblée, soit dans les formes de la délibération, la chambre des nonces est par cela même dissoute, et le roi ordonne de nouvelles élections.

XXXI. Le cas de la dissolution de la chambre des nonces arrivant, la loi des finances est prorogée pour une année, et les lois civiles ou criminelles continuent à être exécutées sans modification ni changement.

XXXII. Lorsque le sénat a refusé sa sanction à une loi, le roi peut également, et dans tous les cas, nommer de nouveau sénateur et renvoyer ensuite la loi au sénat.

Néanmoins, le sénat ne peut se trouver composé de plus de six évêques, douze palatins et douze castellans.

XXXIII. Lorsque le roi a usé du droit établi par l'article ci-dessus, les places qui viennent à vaquer dans le sénat parmi les palatins et les castellans, ne sont pas remplies jusqu'à ce que le sénat soit réduit au nombre fixé par l'art. XXIII.

XXXIV. Lorsque le sénat a donné son approbation à une loi, ou que le roi, nonobstant les motifs de la délibération du sénat, en a ordonné la promulgation, ce projet est déclaré loi et immédiatement obligatoire.

\section{TITRE VI.}

De la chambre des Nonces

Art. XXXV. La chambre des nonces est composé :

10 De soixante nonces nommés par les diétines ou assemblées des nobles de chaque district à raison d'un nonce par district.

Les nonces doivent avoir au moins 24 ans accomplis, jouir de leurs droits, ou être émancipés.

$2^{\circ}$ De quarante députés des communes.

XXXVI. Tout le territoire du duché de Varsovie est partagé en quarante assemblées communales, savoir : huit pour la ville de Varsovie, et trentedeux pour le reste du territoire.

XXXVII. Chaque assemblé communale doit comprendre au moins six cents citoyens ayant droit de voter.

XXXVIII. Les membres de la chambre des nonces restent en fonctions pendant neuf ans. Ils sont renouvelés par tiers tous les trois ans.

En conséquence, et pour la première fois seulement, un tiers des membres de la chambre des nonces, ne restera en fonctions que pendant trois ans, et un autre tiers pendant six ans.

La liste des membres sortant à ces deux époques, sera formée par le sort.

XXXIX. La chambre des nonces est présidée par un maréchal choisi dans son sein et nommé par le roi.

$\mathrm{XL}$. La chambre des nonces délibère sur les projets de lois, qui sont ensuite transmis à la sanction du sénat.

$\mathrm{XLI}$. Elle nomme à chaque session, au scrutin secret et à la majorité des suffrages, trois commissions composées chacune de cinq membres, savoir :

Commission des finances ;

Commission de législation civile ; 
Commission de législation criminelle.

Le maréchal président de la chambre des nonces donne communication au Conseil-d'État, par un message, de la nomination desdites commissions.

XLII. Lorsqu'un projet de loi a été rédigé au Conseil-d'État, il en est donné communication à la commission que l'objet de la loi concerne, par le ministre du département auquel cet objet est relatif, et par l'intermédiaire des maîtres des requêtes attachés au Conseil-d'État.

Si la commission a des observations à faire sur le projet de loi, elle se réunit chez le dit ministre. Les maîtres des requêtes chargés de la communication du projet de loi sont admis à ces conférences.

XLIII. Si la commission persiste dans ses observations, et demande des modifications au projet de loi, il en est fait rapport par le ministre au Conseil-d'État.

Le Conseil-d'État peut admettre les membres de la commission à discuter dans son sein les dispositions du projet de loi qui ont paru susceptibles de modifications.

XLIV. Le Conseil-d'État ayant pris connaissance des observations de la commission, soit par le rapport du ministre, soit par la discussion qui aura eu lieu dans son sein, arrête définitivement la rédaction du projet de loi, qui est transmis à la chambre des nonces pour y être délibéré.

XLV. Les membres du Conseil-d'État sont membres nés de la chambre des nonces. Ils y ont séance et voix délibérative.

XLVI. Les membres du Conseil-d'État et les membres de la commission des nonces ont seuls le droit de porter la parole dans la chambre soit dans le cas où le conseil et la commission sont d'accord sur le projet de loi, pour en fait ressortir les avantages, soit en cas de dissentiment pour en relever ou combattre les inconvénients.

Aucun autre membre ne peut prendre la parole sur le projet de loi.

XLVII. Les membres de la commission peuvent manifester leur opinion individuelle sur le projet de loi, soit qu'ils aient été de l'avis de la majorité de la commission, soit que leur opinion ai été celle de la minorité.

Les membres du Conseil-d'État, au contraire, ne peuvent parler qu'en faveur du projet de loi arrêté au Conseil.

XLVIII. Lorsque le maréchal-président de la chambre des nonces juge que la matière est assez éclaircie, il peut fermer la discussion et mettre le projet de loi en délibération.

La chambre délibère en scrutin secret et à la majorité absolue des suffrages.

XLIX. La loi ayant été délibérée, la chambre des nonces transmet aussitôt au sénat.

\section{TITRE VII.}

Des Diétines et Assemblées communales.

Art. L. Les diétines, ou assemblées de district, sont composées des nobles du district.

LI. Les assemblées communales sont composées des citoyens propriétaires non nobles, et des autres citoyens qui auront d'en faire partie, comme il sera dit ci-après.

LII. Les diétines et les assemblées communales sont convoquées par le roi. Le lieu, le jour de leur réunion, les opérations auxquelles elles doivent procéder et la durée de leur session, sont exprimés dans les lettres de convocation. 
LIII. Nul ne peut être admis à voter s'il n'est âgé de vingt et un ans accomplis, s'il ne jouit de ses droits, ou n'est émancipé. L'émancipation pourra désormais avoir lieu à vingt et un ans, nonobstant toutes lois et usages contraires.

LIV. Chaque diétine, ou assemblée de district nomme un nonce, et présente des candidats pour les conseils de département et de district, et pour les justices de paix.

LV. Les diétines sont présidées par un maréchal nommé par le roi.

LVI. Elles sont divisées en dix séries. Chaque série est composée de districts séparés les uns des autres par les territoires d'un ou plusieurs districts. Deux séries ne peuvent être convoquées en même temps.

LVII. Les députés des communes sont nommés par les assemblées communales.

Elles présentent une liste double de candidats pour les conseils municipaux.

LVIII. Ont droit de voter dans les assemblées communales ;

10 Tout citoyen propriétaire non noble ;

$2^{\circ}$ Tout fabricant et chef d'atelier, tout marchand ayant un fonds de boutique, ou magasin équivalent à un capital de 10,000 florins de Bologne ;

$3^{\circ}$ Tous les curés et vicaires ;

$4^{\circ}$ Tout artiste, et citoyen distingué par ses talents; ses connaissances, ou par des services rendus, soit au commerce, soit aux arts ;

$5^{\circ}$ Tous sous-officier et soldat qui, ayant reçu des blessures ou fait plusieurs campagnes, aurait obtenu sa retraite ;

$6^{\circ}$ Tous sous-officier et soldat en activité de service ayant obtenu des distinctions pour sa bonne conduite ;

$7^{\circ}$ Les officiers de tout grade.

Lesdits officiers, sous-officiers et soldats, actuellement en activité de service qui se trouveraient en garnison dans la ville où l'assemblée communale serait réunie, ne pourraient jouir, dans ce cas seulement, du droit accordé par le présent article.

LIX. La liste des votants propriétaires est dressée par la municipalité, et certifiée par les receveurs des contributions.

Celle des curés et vicaires est dressée par le préfet, et visée par le ministre de l'intérieur.

Celle des officiers, sous-officiers, soldats, désignés dans l'article cidessus, est dressée par le préfet, et visée par le ministre de la guerre.

Celle des fabricants et chefs d'atelier et des marchands ayant un fonds de boutique, magasin ou établissements de fabrique d'un capital de dix mille florins de Pologne, et celle des citoyens distingués par leurs talents, leurs connaissances et des services rendus soit aux sciences, aux arts, soit au commerce, sont dressées par le préfet et arrêtés chaque année par le sénat.

Les citoyens qui se trouvent dans le dernier des cas énoncés ci-dessus, peuvent adresser directement leurs pétitions au sénat, avec les pièces justificatives de leurs demandes.

LX. Le sénat, dans tous les cas où il a lieu de soupçonner des abus dans la formation des listes, peut ordonner qu'il en soit formé de nouvelles.

LXI. Les assemblées communales ne peuvent être convoquées en même tems, dans toute l'étendue d'un district. II y aura toujours un intervalle de huit jours entre la réunion de chacune d'elles, à l'exception néan- 
moins de celles de la ville de Varsovie, qui peuvent être convoquées en même tems, au nombre de deux seulement.

LXII. Les assemblées communales sont présidées par un citoyen nommé par le roi.

LXIII. II ne peut y avoir lieu, dans les diétines ou dans les assemblées communales, à aucune discussion de quelque nature qu'elle puisse être, à aucune délibération, de pétition, ou de remontrance.

Elles ne doivent s'occuper que de l'élection, soit des députés, soit des candidats, dont le nombre est désigné d'avance, comme il est dit ci-dessus, par les lettres de convocation.

\section{TITRE VIII}

Division du territoire et administration

Art. LXIV. Le territoire demeure divisé en six départements.

LXV. Chaque département est administré par un préfet.

II y a dans chaque département, un conseil des affaires contentieuses, composé de trois membres au moins, et de cinq au plus, et un conseil général de département, composé de seize membres, au moins, et de vingtquatre au plus.

LXVI. Les districts sont administrés par un sous-préfet.

Il y a dans chaque district, un conseil de district composé de neuf membres, au moins, et de douze au plus.

LXVII. Chaque municipalité est administrée par un maire ou président ;

II y a dans chaque municipalité, un conseil municipal, composé de dix membres pour deux mille cinq cents habitants et au-dessous; de vingt pour cinq mille habitants et au-dessous; i et de 15 pour les villes dont la population excède cinq mille habitants.

LXVIII. Les préfets, conseillers de préfecture, sous-préfets et maires, sont nommés par le roi, après présentation préalable.

Les membres des conseils de départements, et des conseils de districts sont nommés par le roi, sur une liste double de candidats présentés par les diétines de district. Ils sont renouvelles par moitié, tous les deux ans.

Les membres des conseils municipaux sont nommés par le roi, sur une liste double de candidats présentés par les assemblées communales.

Ils sont renouvelés par moitié tous les deux ans.

Les conseils de département et de district, et les conseils municipaux, nomment un président choisi dans leur sein.

\section{TITRE IX.}

Ordre Judiciaire

Art. LXIX. Le Code Napoléon formera la loi civile du duché de Varsovie.

LXX. La procédure est publique en matière civile et criminelle.

LXXI. II y a une justice de paix par district ;

Un tribunal civil de première instance par département ;

Une cour de justice criminelle par deux départements ;

Une seule cour d'appel pour tout le duché de Varsovie.

LXXII. Le Conseil-d'État, auquel sont réunis quatre maîtres de requêtes nommés par la loi, fait les fonctions de cour de cassation.

LXXIII. Les juges de paix sont nommés par le roi sur une liste triple de candidats présentés par les diétines de districts. Ils sont renouvelés par tiers tous les deux ans.

LXXIV. L'ordre judiciaire est indépendant. 
LXXV. Les juges des tribunaux de première instance, des cours criminelles et des cours d'appel, sont nommés par le roi et à vie.

LXXVI. La cour d'appel peut, soit sur la dénonciation du procureur royal, soit sur celle d'un de ses présidents, demander au roi la destitution d'un juge d'un tribunal de première instance ou d'une cour criminelle qu'elle croît coupable de prévarication dans l'exercice de ses fonctions.

La destitution d'un juge de la cour d'appel peut être demandée par le Conseil-d'État, faisant les fonctions de cour de cassation.

Dans ces cas seuls, la destitution d'un juge peut être prononcée par le roi.

LXXVII. Les jugements des cours et des tribunaux sont rendus au nom du roi.

LXXVIII. Le droit de faire grâce appartient au roi: seul il peut remettre ou commuer la peine.

\section{TITRE X}

De la force armée

Art. LXXIX. La force armée sera composée de 30.000 hommes de toute arme, présents sous les armes, les gardes nationales non comprises.

LXXX. Le roi pourra appeler en saxe une partie des troupes du duché de Varsovie, en les faisant remplacer par un pareil nombre de troupes saxonnes.

LXXXI. Dans le cas où les circonstances exigeraient qu'indépendamment des troupes du duché de Varsovie, le roi envoyât sur le territoire de ce duché, d'autres corps de troupes saxonnes, il ne pourrait être établi à cette occasion aucune autre imposition ou charge publique que celles qui auraient été autorisées par la loi des finances.

\section{TITRE XI}

\section{Dispositions générales}

Art. LXXXII. Les titulaires de toutes les charges et fonctions qui ne sont point à vie, y compris la vice-royauté, sont révocables à la volonté du roi, les nonces exceptés.

LXXXIII. Aucun individu s'il n'est pas citoyen du duché de Varsovie, ne peut être appelé à y remplir des fonctions, soit ecclésiastiques, soit civiles, soit judiciaires.

LXXXIV. Tous les actes du gouvernement, de la législation, de l'administration et des tribunaux sont écrits en langue nationale.

LXXXV. Les Ordres civils et militaires précédemment existants en Pologne, sont maintenus. Le roi est le chef de ces Ordres.

LXXXVI. Le présent Statut constitutionnel sera complété par des règlements émanés du roi et discutés dans son Conseil-d'État.

LXXXVII. Les lois et règlements d'administration publique seront publiés au Bulletin des lois, et n'ont pas besoin d'autre forme de publication pour devenir obligatoires.

\section{TITRE XII}

Dispositions transitoires

Art. LXXXVIII. les impositions actuellement existantes, continueront à être perçues jusqu'au ler janvier 1809.

LXXXIX. II ne sera rien changé au nombre et à l'organisation actuels des troupes, jusqu'à ce qu'il ait été statué à cet égard par la première diète générale qui sera convoquée. 
Les membres de la commission de gouvernement, Signé, MALACKOWSKI, président; GUTACKOWSKI, STANISLAS POTOCKI, DZIALINTSKI, WIBICKI, BILINSKI, SOBOLEWSKI, LUSZCREWSKI, secrétaire-général.

NAPOLÉON, par la grâce de Dieu et les constitutions, Empereur des Français, Roi d'Italie, Protecteur de la Confédération du Rhin; nous avons approuvé et approuvons le Statut constitutionnel ci-dessus, qui nous a été présenté en exécution de l'article $V$ du traite de Tilsitt, et que nous considérons comme propre à remplir nos engagements envers les peuples de Varsovie et de la Grande Pologne, en conciliant leurs libertés et privilèges avec la tranquillité des États voisins.

Donné au Palais royal de Dresde, le 22 juillet 1807. Signé, NAPOLÉON.

Par l'Empereur,

Le ministre secrétaire-d'état, Signé, H. B. Maret.

Recebido para publicação em março de 2008

Aprovado em abril de 2008 